\title{
Investigation of Combined Effect of Mixture Variables on Mechanical Properties of Cement Treated Demolition Waste
}

\author{
Dongxing Xuan ${ }^{1, *}$, Lambert J. M. Houben ${ }^{1}$, André A. A. Molenaar ${ }^{1}$, and Zhonghe Shui ${ }^{2}$ \\ 1 Faculty of Civil Engineering and Geosciences, Delft University of Technology, Stevinweg 1, 2628 CN \\ Delft, the Netherlands \\ 2 School of Materials Science and Engineering, Wuhan University of Technology, Luoshi Road No. 122, \\ 430070 Wuhan, People's Republic of China \\ Email: d.xuan@tudelft.nl*
}

\begin{abstract}
One of high efficient ways to reuse the recycled construction and demolition waste $(\mathrm{CDW})$ is to consider it as a road base material. The recycled CDW however is mainly a mix of recycled masonry and concrete with a wide variation in composition. This results that the mechanical properties of cement treated demolition waste are not only determined by cement content and degree of compaction, but also by the composition ratio of masonry to concrete. This paper investigates the combined effect of those three mixture variables on the mechanical properties of cement treated demolition waste by using response surface technique. The evaluated mechanical properties include the unconfined compressive strength (UCS), the elastic modulus and their ratio. Analytical results indicate that increasing the degree of compaction is an economic technique to obtain the required mechanical properties, but it is not an efficient method to enhance the admissible elastic strain (the ratio of UCS to E). Considering the pavement structure design with cement treated demolition base, improvement of its structural performance needs adjusting the masonry content and the cement content.
\end{abstract}

Keywords: Construction and demolition waste, mechanical properties, mixture variables, response surface technique.

ENGINEERING JOURNAL Volume 16 Issue 4

Received 2 January 2012

Accepted 14 March 2012

Published 1 July 2012

Online at http://www.engj.org/

DOI:10.4186/ej.2012.16.4.107

This paper is based on the oral presentation at the $7^{\text {th }}$ International Conference on Road and Airfield Pavement Technology, ICPT 2011, in Bangkok, Thailand, 3-5 August 2011. 


\section{Introduction}

Cement treated granular materials have been widely used as semi-rigid base/subbase courses for either flexible or rigid pavements. Traditionally, they are produced by using coarse natural or crushed aggregates. With serious environmental impacts of construction and demolition waste (CDW) and a lack of natural resources, the recycled CDW is now promoted in some countries as road base/subbase materials [1].

It has been found that some mixture variables influence the mechanical properties of cement treated granular materials such as cement content, degree of compaction, curing time and so on [2]. In this study, $\mathrm{CDW}$ has been used as granulates. Because the recycled CDW is a mix of recycled masonry aggregates (RMA) and recycled concrete aggregates (RCA), the ratio of RMA to RCA certainly influences its mechanical properties as well [3]. In order to optimize the mixture proportioning of cement treated demolition waste (CTDW), it is of great importance to explore the relations between mixture variables and mechanical properties.

Being one of a structural pavement layer, the mechanical properties of the road base are very important for structural designs [4]. In general, the unconfined compressive strength (UCS) is generally considered as the most important mixture design index. Meanwhile, for pavement design purposes, the stress-strain behaviour of the material used for base courses should also be known, especially its elastic modulus. It is an important index used for linear-elastic multi-layer pavement design system and for the estimation of the shrinkage stress. For a given pavement structure with cement treated base, the lower the elastic modulus of cement treated material, the lower the flexural rigidity for cement treated base and the lower the tensile stress at the bottom of cement treated base will be. As a result, if the (elastic) admissible strain of cement treated granular materials, defined as the ratio of strength over modulus given by Eq. (1), is high, it is more desirable for its pavement application. Therefore, the ratio of strength over modulus is considered as an indicator to design this material, which is given by:

$$
\varepsilon=\frac{f}{E}
$$

where $\varepsilon$ is the admissible strain of the material; $f$ is the strength of the material; $E$ is the elastic modulus of the material.

The objective of this paper is to investigate the combined effect of mixture variables on the UCS, the elastic modulus and their ratio by using response surface technique. Mixture variables include the cement content, the degree of compaction and the RMA content. By exploring those response surfaces and contour plots, the mixture composition of CTDW can be optimized to obtain the required mechanical properties.

\section{Experimental Design}

Three mixture variables were selected to investigate their combined effects on the mechanical properties of CTDW. They are the ratio of RMA to RCA, the cement content and the degree of compaction. For each variable, different levels were applied below.

In this research, four levels of the ratio of RMA to RCA content (by mass) chosen were $0 \%: 100 \%$, 35\%:65\%, 65\%:35\%, 100\%:0\%, respectively. A central composite design was employed to consider the influences of cement content (C) and degree of compaction (DC) for CTDW with a given RMA content [5]. Such a factorial design is constructed by considering centre points and star points, which is given in Table 1 . $+\alpha, 1,0,-1$ and $-\alpha$ present the application levels of variables. It is recommended to use 5 specimens at the central point $\left(\mathrm{C}_{0} \mathrm{DC}_{0}\right)$ and one at each other point. Based on previous researches, the cement content chosen for cement treated aggregate materials varied from $2.5 \%(-\alpha)$ to $5.5 \%(+\alpha)$. The degree of compaction ranges from $97 \%(-\alpha)$ to $105 \%(+\alpha)$ referred to the standard proctor compaction [6]. Therefore, the mixture in the central point was designed with a cement content of $4 \%$ (level is 0 ) and a degree of compaction of $101 \%$ (level is 0 ). The star points were selected by Eq. (2) and Eq. (3) that establish the relationship between all levels.

$$
\sqrt{2}\left(C_{+1}-C_{0}\right)=\frac{1}{2}\left(C_{\alpha}-C_{-\alpha}\right)
$$




$$
\sqrt{2}\left(D C_{+1}-D C_{0}\right)=\frac{1}{2}\left(D C_{\alpha}-D C_{-\alpha}\right)
$$

Table 1. Design for 2 factors at 5 levels in 9 runs.

\begin{tabular}{lcc}
\hline \multirow{2}{*}{ Items } & Two variables and their application levels \\
\cline { 2 - 3 } & $\mathbf{C}$ & DC \\
\hline $\mathrm{C}_{-\alpha} \mathrm{DC}_{0}$ & $-\alpha$ & 0 \\
$\mathrm{C}_{+\alpha} \mathrm{DC}_{0}$ & $+\alpha$ & 0 \\
$\mathrm{C}_{0} \mathrm{DC}_{-\alpha}$ & 0 & $-\alpha$ \\
$\mathrm{C}_{0} \mathrm{DC}_{+\alpha}$ & 0 & $+\alpha$ \\
$\mathrm{C}_{0} \mathrm{DC}_{0}$ & 0 & 0 \\
\hline $\mathrm{C}_{-1} \mathrm{DC}_{-1}$ & -1 & -1 \\
$\mathrm{C}_{+1} \mathrm{DC}_{-1}$ & +1 & -1 \\
$\mathrm{C}_{-1} \mathrm{DC}_{+1}$ & -1 & +1 \\
$\mathrm{C}_{+1} \mathrm{DC}_{+1}$ & +1 & +1 \\
\hline
\end{tabular}

Note: $C$ means the cement content; DC means the degree of compaction. $+\alpha, 1,0,-1$ and $-\alpha$ present the application levels of variables.

\section{Materials Used and Experimental Procedures}

\subsection{Recycled Materials}

Two different recycled aggregates, which were collected at two Dutch companies, were used in this study. One is recycled crushed concrete aggregates (RCA) and the other is recycled crushed masonry aggregates (RMA). Both recycled aggregates were divided into six fractions: $31.5-22.4 \mathrm{~mm}, 22.4-16.0 \mathrm{~mm}, 16.0-8.0 \mathrm{~mm}$, 8.0-5.6 mm, 5.6-2.0 mm, $<2.0 \mathrm{~mm}$. The physical properties of their different fractions are determined in accordance with the European Standard EN 1097-6, Annex C, and they are listed in Table 2. In addition to the recycled aggregates, EN 42.5 Portland cement and tap water were used to prepare the mixtures.

Table 2. Physical properties of crushed masonry and crushed concrete.

\begin{tabular}{|c|c|c|c|c|c|c|c|}
\hline & \multirow{2}{*}{ Test items } & \multicolumn{6}{|c|}{ Fractions (mm) } \\
\hline & & 31.5-22.4 & 22.4-16.0 & $16.0-8.0$ & $8.0-5.6$ & $5.6-2.0$ & $2.0-0.063$ \\
\hline \multirow{3}{*}{ RMA } & Apparent Density $\left(\mathrm{g} / \mathrm{cm}^{3}\right)$ & 2.299 & 2.299 & 2.369 & 2.418 & 2.458 & 2.593 \\
\hline & Particle Density $\left(\mathrm{g} / \mathrm{cm}^{3}\right)$ & 1.934 & 1.931 & 1.954 & 1.976 & 1.920 & 1.914 \\
\hline & Water absorption in 48 hours (\%) & 8.19 & 8.27 & 8.98 & 9.26 & 11.40 & 13.67 \\
\hline \multirow{3}{*}{ RCA } & Apparent Density $\left(\mathrm{g} / \mathrm{cm}^{3}\right)$ & 2.533 & 2.512 & 2.555 & 2.583 & 2.597 & 2.596 \\
\hline & Particle Density $\left(\mathrm{g} / \mathrm{cm}^{3}\right)$ & 2.354 & 2.313 & 2.322 & 2.336 & 2.311 & 2.046 \\
\hline & Water absorption in 48 hours $(\%)$ & 2.99 & 3.41 & 3.91 & 4.10 & 4.76 & 10.34 \\
\hline
\end{tabular}

The target gradation for the mix granulates was designed by Eq. (4). Compared to the Fuller's curve $(\mathrm{n}=0.45)$, the target curve has less fines in the mixture. The reason why this gradation is chosen is that RCA does not contain too much fines in practice. In order to be able to reuse as much as crushed concrete aggregates, the target curve was selected for practical reasons.

$$
P=(100-F) \cdot \frac{d^{n}-0.063^{n}}{D^{n}-0.063^{n}}+F
$$

where $P=$ percentage passing sieve size $d, \%$; 
$\mathrm{D}=$ maximum particle size, $\mathrm{mm}(31.5 \mathrm{~mm}$ in this study);

$\mathrm{F}=$ fines content, $\%(\mathrm{~F}=2.24$, close to the fines content $(<0.063 \mathrm{~mm})$ in crushed concrete aggregates);

$\mathrm{n}=$ a parameter describing the shape of the grading curve ( $\mathrm{n}=0.45$ in this study).

\subsection{Moisture Content in Mixtures}

In accordance with Annex B of the European Standard EN 13286-2 (One-Point-Proctor test), four types of CTDW mixtures with $4 \%$ of cement content by mass of total aggregates were compacted in order to obtain the optimum moisture content. The obtained dry density is then referred to as the $100 \%$ degree of compaction in this study. Table 3 lists the optimum moisture content and the corresponding dry density of CTDW.

Table 3. Moisture content and dry density of CTDW by One-Point-Proctor test.

\begin{tabular}{lccr}
\hline $\begin{array}{l}\text { Ratio of RMA } \\
\text { to RCA }\end{array}$ & $\begin{array}{c}\text { Optimum moisture } \\
\text { content (\%) }\end{array}$ & $\begin{array}{r}\text { Dry density } \\
\mathbf{( g / \mathbf { c m } ^ { 3 } )}\end{array}$ & $\begin{array}{r}\text { Appearance } \\
\text { of fresh } \\
\text { CTDW }\end{array}$ \\
\hline $100 \%: 0 \%$ & 11.81 & 1.662 & A little \\
$65 \%: 35 \%$ & 10.94 & 1.754 & shinny; no \\
$35 \%: 65 \%$ & 10.44 & 1.834 & bleeding \\
\hline $0 \%: 100 \%$ & 9.54 & 1.907 & \\
\hline
\end{tabular}

It can be seen that with an increase of the RMA content, more water is needed to obtain a good workability. Meanwhile, the dry density of CTDW at $100 \%$ degree of compaction gradually decreases with increasing the RMA content. This is due to the high water absorption of the recycled RMA and its low density shown in Table 2 . Using mathematic relations, optimum moisture content ( $\left.\mathrm{W}_{\text {optimum }}\right)$ and dry density at $100 \%$ degree of compaction $\left(\mathrm{D}_{100 \%}\right)$ are related to the RMA content:

$$
\begin{array}{ll}
W_{\text {optimum }}=0.0222 \cdot M+9.5724 & \left(\mathrm{R}^{2}=0.994\right) \\
D_{100 \%}=-0.0025 \cdot M+1.9126 & \left(\mathrm{R}^{2}=0.997\right)
\end{array}
$$

where $\mathrm{W}_{\text {optimum }}$ is optimum moisture content of CTDW by the whole mass of aggregates, $\%$; $\mathrm{D}_{100 \%}$ is the dry density of CTDW at $100 \%$ degree of compaction, $\mathrm{g} / \mathrm{cm}^{3} ; \mathrm{M}$ is the RMA content by mass of the total aggregates, $\%$;

For a CTDW mixture with a specific RMA content, its optimum moisture content is fixed for the specimen preparation. The required degree of compaction for the specimen varies by adjusting the compaction effect. The following equation is used to calculate the designed density:

$$
D_{\text {designed }}=\frac{D C_{\text {designed }} \times D_{100 \%}}{100}
$$

where $\mathrm{DC}_{\text {designed }}$ is the designed degree of compaction, $\%$; $\mathrm{D}_{\text {designed }}$ is the designed dry density, $\mathrm{g} / \mathrm{cm}^{3}$.

\subsection{Specimen Preparation}

All CTDW specimens were prepared according to the designed composition and moisture content. In the laboratory CTDW was firstly mixed by using a laboratory mixer. The fresh mixture with the required mass was then compacted in three layers in a mould of $\Phi 150 \times 150 \mathrm{~mm}$ by using a vibrating hammer. After 24hours curing in the mould, all specimens were demolded and subjected to a fog-room curing at $20^{\circ} \mathrm{C}$. The curing regime referred to EN 14227-1 Annex C. When the curing time reached 28 days, all specimens were tested. 


\subsection{Determination of Mechanical Properties}

The UCS of the specimen was measured by using a MTS actuator of $245 \mathrm{kN}$ in the axial displacement control mode. The displacement rate was controlled by three linear variable differential transformers (LVDTs) along the axial direction of the specimen. A friction reduction system was used to obtain uniform radial deformations over the height of the specimen. The controlled strain rate is $10^{-5} / \mathrm{second}$. The data of the force and the deformation are automatically recorded by a MP3 program. The elastic modulus (E) of CTDW is considered as the tangent modulus measured along the linear portion of the stress-strain diagram. Figure 1 shows the experimental compression test-up.

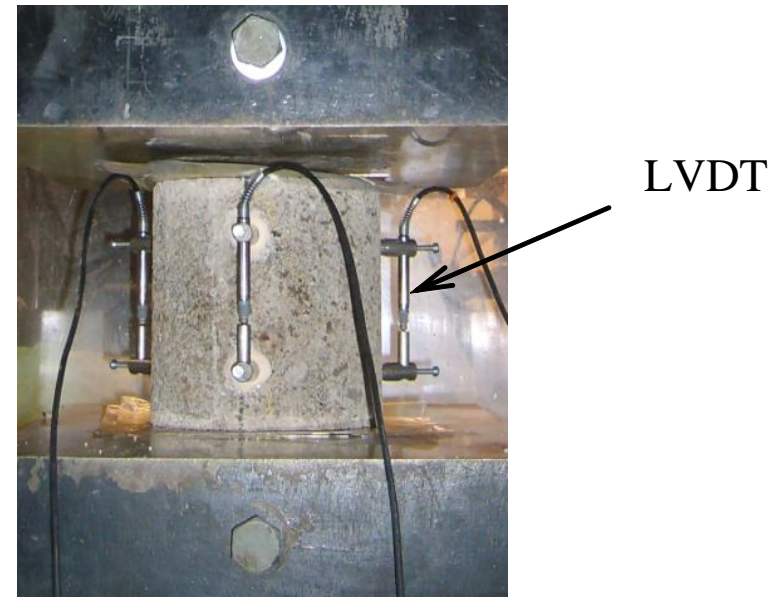

Fig. 1. Set-up of compression testing.

\section{Estimation Models of Mechanical Properties}

\subsection{Experimental Results}

Table 4 lists all experimental data obtained on basis of the experimental design mentioned above.

\subsection{Estimation Models}

In previous researches, some relationships have been presented to indicate that the UCS linearly increases with the cement content and has an exponential relation with the dry density [6]. By combining those findings, the following prediction models for the UCS and $\mathrm{E}_{\text {static }}$ of CTDW were obtained:

$$
\begin{array}{cl}
U C S & =0.0747 \cdot \frac{C}{W_{\text {optimum }}} \cdot D_{\text {designed }}^{8} \cdot e^{0.0088 \cdot M} \quad(\mathrm{MPa}) \quad\left(\mathrm{R}^{2}=0.946\right) \\
E_{\text {static }} & =161.3 \cdot\left(\frac{C}{W_{\text {optimum }}}\right)^{0.71} \cdot D_{\text {designed }}^{7.4} \cdot e^{0.0053 \cdot M} \quad(\mathrm{MPa}) \quad\left(\mathrm{R}^{2}=0.826\right)
\end{array}
$$

Where, $\mathrm{C}$ is the cement content by the whole mass of aggregates, $\%$

By further combining Eq. (5), (6), and (7), Eq. (10) and (11) are developed:

$$
\begin{gathered}
U C S=0.0747 \cdot C \cdot\left(\frac{D C_{\text {designed }}}{100}\right)^{8} \cdot \frac{(-0.0025 \cdot M+1.9126)^{8}}{0.0222 \cdot M+9.5724} \cdot e^{0.0088 \cdot M} \\
E_{\text {static }}=161.3 \cdot C^{0.71} \cdot\left(\frac{D C_{\text {designed }}}{100}\right)^{7.4} \cdot \frac{(-0.0025 \cdot M+1.9126)^{7.4}}{(0.0222 \cdot M+9.5724)^{0.71}} \cdot e^{0.0053 \cdot M}
\end{gathered}
$$


Table 4. Mechanical properties of CTDW at 28 days.

\begin{tabular}{|c|c|c|c|c|c|c|c|c|c|c|}
\hline \multirow[t]{2}{*}{ Items } & \multicolumn{3}{|c|}{ Variables } & \multicolumn{2}{|c|}{$\begin{array}{l}\text { Mechanical } \\
\text { properties }\end{array}$} & \multicolumn{3}{|c|}{ Variables } & \multicolumn{2}{|c|}{$\begin{array}{l}\text { Mechanical } \\
\text { properties }\end{array}$} \\
\hline & $\begin{array}{l}\mathrm{M} \\
(\%)\end{array}$ & $\begin{array}{c}\mathrm{D} \\
\left(\mathrm{g} / \mathrm{cm}^{3}\right)\end{array}$ & $\begin{array}{l}\mathrm{W} \\
(\%)\end{array}$ & $\begin{array}{l}\mathrm{E}_{\text {static }} \\
(\mathrm{MPa})\end{array}$ & $\begin{array}{l}\mathrm{UCS} \\
(\mathrm{MPa})\end{array}$ & $\begin{array}{l}\mathrm{M} \\
(\%)\end{array}$ & $\begin{array}{c}\mathrm{D} \\
\left(\mathrm{g} / \mathrm{cm}^{3}\right)\end{array}$ & $\begin{array}{l}\mathrm{W} \\
(\%)\end{array}$ & $\begin{array}{l}E_{\text {static }} \\
(\mathrm{MPa})\end{array}$ & $\begin{array}{l}\mathrm{UCS} \\
(\mathrm{MPa})\end{array}$ \\
\hline $\mathrm{C}_{0} \mathrm{D}_{0}-1$ & & 1.914 & & 13429 & 6.08 & & 1.782 & & 7737 & 4.58 \\
\hline $\mathrm{C}_{0} \mathrm{D}_{0}-2$ & & 1.909 & & 9685 & 5.39 & & 1.775 & & 8057 & 4.49 \\
\hline $\mathrm{C}_{0} \mathrm{D}_{0}-3$ & & 1.921 & & 12414 & 6.10 & & 1.773 & & 6373 & 4.51 \\
\hline $\mathrm{C}_{0} \mathrm{D}_{0}-4$ & & 1.890 & & 9797 & 5.25 & & 1.771 & & 8274 & 4.43 \\
\hline $\mathrm{C}_{0} \mathrm{D}_{0}-5$ & & 1.917 & & 9797 & 5.15 & & 1.765 & & 8042 & 4.11 \\
\hline $\mathrm{C}_{-\alpha} \mathrm{D}_{0}$ & & 1.901 & & 8173 & 3.84 & & 1.760 & & 4929 & 2.88 \\
\hline $\mathrm{C}_{+\alpha} \mathrm{D}_{0}$ & 0 & 1.937 & 9.54 & 14733 & 8.72 & 65 & 1.796 & 10.94 & 10098 & 7.10 \\
\hline $\mathrm{C}_{0} \mathrm{D}_{-\alpha}$ & & 1.793 & & 7998 & 4.04 & & 1.688 & & 3846 & 2.87 \\
\hline $\mathrm{C}_{0} \mathrm{D}_{+\alpha}$ & & 1.975 & & 12125 & 7.18 & & 1.841 & & 9253 & 6.96 \\
\hline $\mathrm{C}_{-1} \mathrm{D}_{-1}$ & & 1.864 & & 8852 & 3.63 & & 1.710 & & 2887 & 2.16 \\
\hline $\mathrm{C}_{-1} \mathrm{D}_{+1}$ & & 1.931 & & 9946 & 4.76 & & 1.804 & & 4030 & 3.75 \\
\hline $\mathrm{C}_{+1} \mathrm{D}_{-1}$ & & 1.863 & & 7571 & 5.34 & & 1.735 & & 9584 & 4.56 \\
\hline $\mathrm{C}_{+1} \mathrm{D}_{+1}$ & & 1.980 & & 16138 & 10.0 & & 1.839 & & 11347 & 6.93 \\
\hline $\mathrm{C}_{0} \mathrm{D}_{0-1}$ & & 1.865 & & 9434 & 5.89 & & 1.682 & & 4232 & 4.08 \\
\hline $\mathrm{C}_{0} \mathrm{D}_{0}-2$ & & 1.869 & & 10591 & 5.40 & & 1.679 & & 6715 & 4.05 \\
\hline $\mathrm{C}_{0} \mathrm{D}_{0}-3$ & & 1.868 & & 9890 & 5.98 & & 1.678 & & 6108 & 3.91 \\
\hline $\mathrm{C}_{0} \mathrm{D}_{0}-4$ & & 1.866 & & 11432 & 5.99 & & 1.690 & & 6838 & 4.58 \\
\hline $\mathrm{C}_{0} \mathrm{D}_{0}-5$ & & 1.856 & & 11255 & 5.74 & & 1.667 & & 6041 & 3.92 \\
\hline $\mathrm{C}_{-\alpha} \mathrm{D}_{0}$ & & 1.860 & & 5786 & 3.84 & & 1.678 & & 2496 & 2.17 \\
\hline $\mathrm{C}_{+\alpha} \mathrm{D}_{0}$ & 35 & 1.890 & 10.44 & 12432 & 8.33 & 100 & 1.700 & 11.81 & 6642 & 5.54 \\
\hline $\mathrm{C}_{0} \mathrm{D}_{-\alpha}$ & & 1.814 & & 6324 & 4.28 & & 1.636 & & 5616 & 3.23 \\
\hline $\mathrm{C}_{0} \mathrm{D}_{+\alpha}$ & & 1.945 & & 14613 & 7.59 & & 1.752 & & 9284 & 6.07 \\
\hline $\mathrm{C}_{-1} \mathrm{D}_{-1}$ & & 1.825 & & 4680 & 2.73 & & 1.640 & & 5533 & 2.35 \\
\hline $\mathrm{C}_{-1} \mathrm{D}_{+1}$ & & 1.901 & & 9469 & 5.44 & & 1.718 & & 6005 & 3.81 \\
\hline $\mathrm{C}_{+1} \mathrm{D}_{-1}$ & & 1.837 & & 10532 & 6.12 & & 1.660 & & 8874 & 4.84 \\
\hline $\mathrm{C}_{+1} \mathrm{D}_{+1}$ & & 1.927 & & 14740 & 9.02 & & 1.746 & & 10163 & 7.34 \\
\hline
\end{tabular}

Note: $M=R M A ; D=d r y$ density; $W=$ water; $E_{\text {static }}=$ static modulus; $U C S=$ compressive strength.

\section{Combined Effects of Mixture Variables on Mechanical Properties}

\subsection{UCS of CTDW in Relation to Mixture Variables}

Figure 2 shows the contour plots of the combined effect of mixture variables on the UCS of CTDW. It can be seen that increasing the degree of compaction can yield an equivalent effect on the UCS of CTDW as increasing the cement content. Moreover, it is quite clear that it is more economic and efficient to achieve a good strength by a good compaction rather than by increasing the cement content. These results are also in agreement with previous findings about the influence of cement content and dry density on cement treated materials [7]. In practice, if the degree of compaction is controlled in the range of $98 \%$ and $102 \%$ and the cement content is between $3.0 \%$ and 5.0\%, the UCS of CTDW can be obtained between $2.0 \mathrm{MPa}$ and 8.0 $\mathrm{MPa}$. This strongly depends on the RMA content.

This study shows that the RMA content is another factor that influences the mechanical performance of CTDW. If there is a $35 \%$ decrease of the RMA content in CTDW, the UCS increases with a factor of about 1.5 times. This effect is equivalent to an increase of the degree of compaction of about $3 \%$ or an increase of the cement content of about $1.5 \%$. 


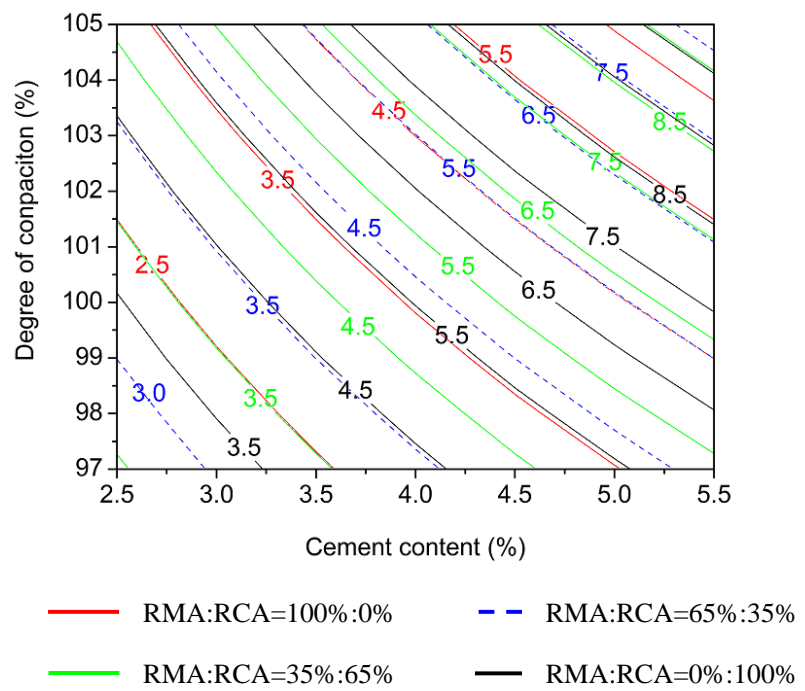

Fig. 2. Contour plots of the combined effect of cement content, degree of compaction and RMA content on the UCS of CTDW.

\subsection{Elastic Modulus of CTDW in Relation to Mixture Variables}

Figure 3 shows the contour plots of the combined effect of the cement content, the degree of compaction and the ratio of RMA to RCA on the $\mathrm{E}_{\text {static }}$ of CTDW. It can be seen that the cement content, the degree of compaction and the RMA content have a similar effect on the $\mathrm{E}_{\text {static }}$ of CTDW as they had on the UCS. In the area for cement content between $3.0 \%$ and $5.0 \%$ and degree of compaction between $97 \%$ and $105 \%$, the elastic modulus of CTDW varies from $4000 \mathrm{MPa}$ to $13000 \mathrm{MPa}$.

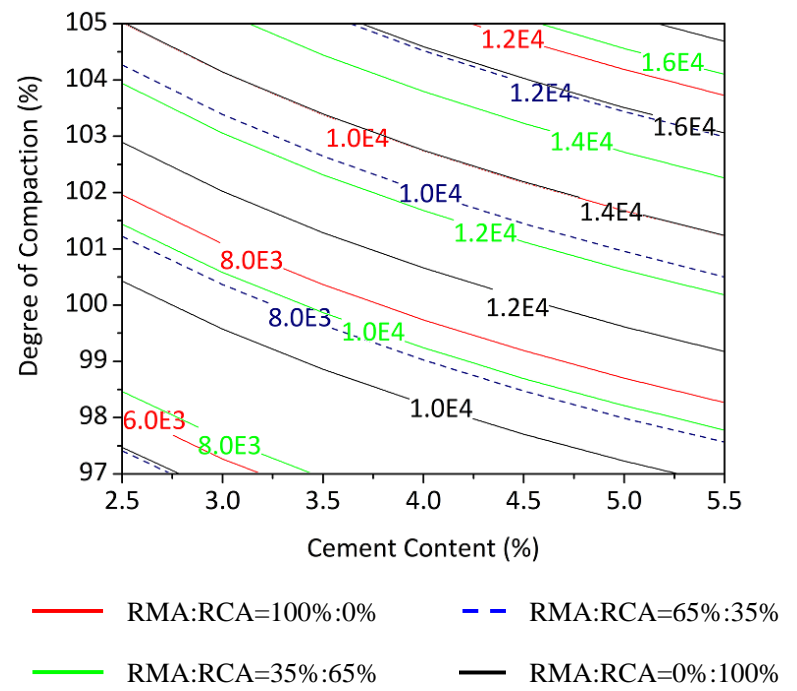

Fig. 3. Contour plots of the combined effect of cement content, degree of compaction and RMA content on the elastic modulus of CTDW.

It is known that on basis of meso-mechanics material models, the elastic modulus of cement based material is controlled by the nature of the material structure. The cement content governs the bonding strength between aggregates and the matrix's strength. The degree of compaction strongly influences the aggregate skeleton that affects the deformation under loading. As shown in Fig. 3, the aggregate type is a factor that influences the skeleton deformation. In practice, the elastic modulus of RMA is from $5 \mathrm{GPa}$ to $18 \mathrm{GPa}$. The elastic modulus of RCA varies from $30 \mathrm{GPa}$ to $60 \mathrm{GPa}$, which is determined by the recycled 
resource [8]. Due to different elastic modulus of the individual aggregates of RMA and RCA, the ratio of RMA to RCA certainly determines the deformation characteristics of CTDW.

\subsection{Ratio of UCS to Elastic Modulus in Relation to Mixture Variables}

Figure 4 shows the response surface and contour plots of the combined effect of the degree of compaction and the cement content on the ratio of UCS to elastic modulus. When increasing the degree of compaction from $97 \%$ to $105 \%$, the ratio of UCS to elastic modulus slightly increases. However, increasing the cement content from $2.5 \%$ to $5.5 \%$ causes an obvious increase of the ratio of UCS to elastic modulus. Comparing to the contour lines, they are nearly vertical. This means that the influence of the degree of compaction on the ratio of UCS to elastic modulus is rather smaller than that of the cement content.

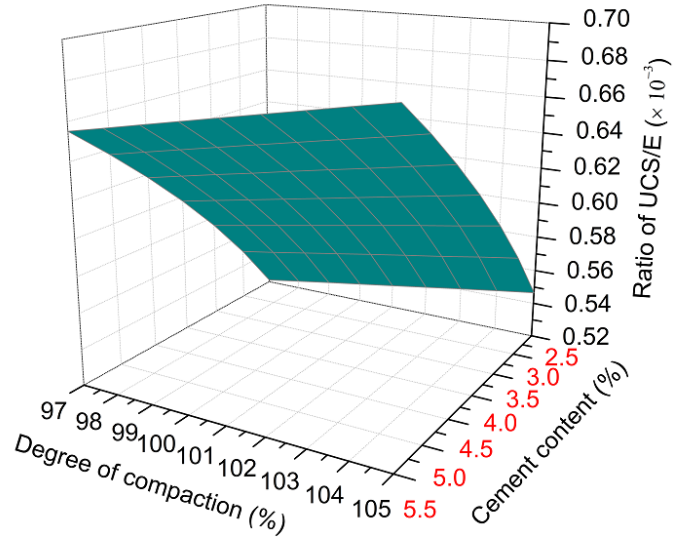

(a) Response surface

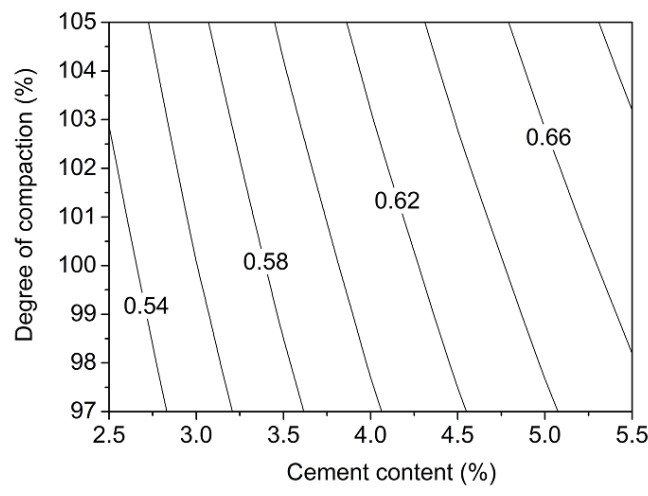

(b) Contour plots

Fig. 4. Response surface and contour curves of the combined effect of degree of compaction and cement content on the ratio of UCS to elastic modulus $(\mathrm{RMA}=65 \%)$.

Considering the RMA content as a unique factorial, Fig. 5 shows the response surface and contour plots of the combined effect of the cement content and the RMA content on the ratio of UCS to elastic modulus. It is found that the cement content and the RMA content play an equally important effect on the ratio of UCS to elastic modulus. That is, to obtain a high value of the ratio of UCS to elastic modulus, it is needed to increase the RMA content and the cement content.

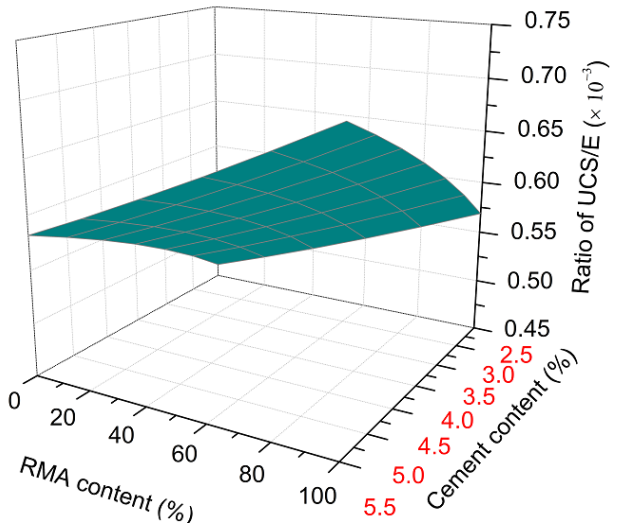

(a) Response surface

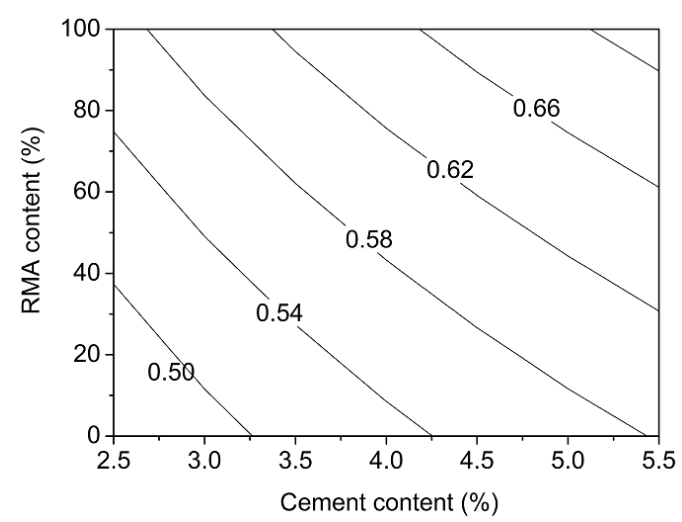

(b) Contour plots

Fig. 5. Response surface and contour curves of the combined effect of RMA content and cement content on the ratio of UCS and elastic modulus (DC= 101\%). 


\subsection{Contour Curves of UCS and Ratio of UCS to Elastic Modulus}

Figure 6 shows the contour curves of UCS and ratio of UCS to elastic modulus. It indicates that for a given demolition waste, a required strength or a required ratio of UCS to elastic modulus can be obtained by adjusting the cement content or the degree of compaction. However, the degree of compaction slightly adjusts the ratio of UCS to elastic modulus. Increasing the degree of compaction can result in the increase of the flexural rigidity and the strength of the CTB layer. Therefore comprehensive consideration for the mixture optimization should be given to the influence of all mixture variables on the UCS and the ratio of UCS to elastic modulus.

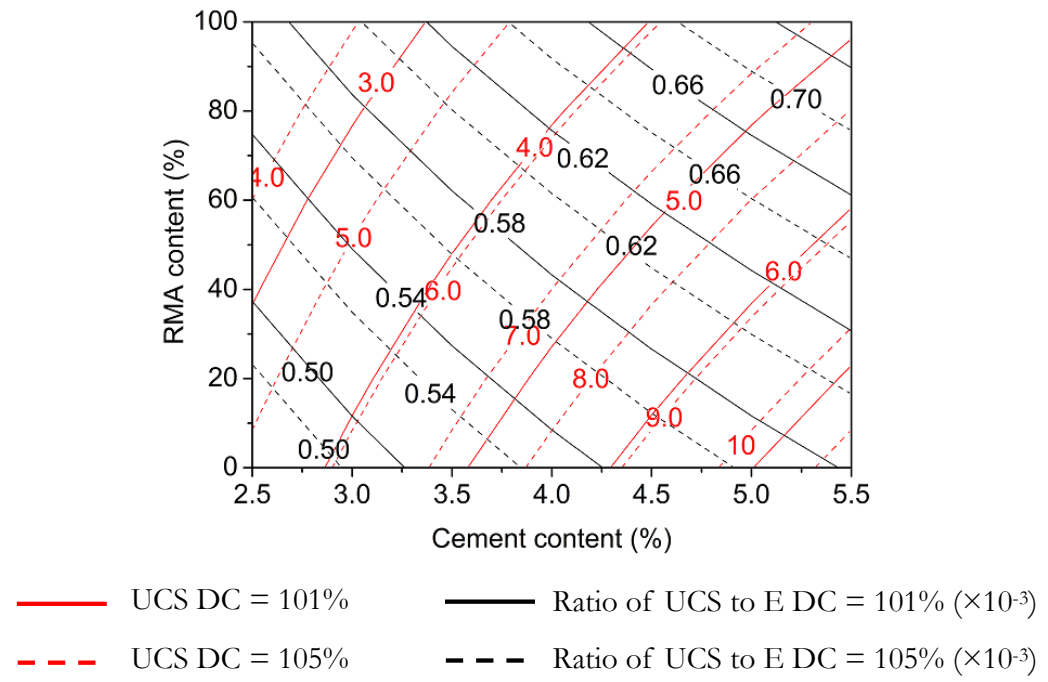

Fig. 6. Contour plots of the combined effect of RMA content, cement content and degree of compaction on the UCS and the ratio of UCS to elastic modulus.

\section{Conclusions}

This study investigated the combined influence of mixture variables on the mechanical properties of cement treated demolition waste by using response surface technique to. Some main findings can be given below:

1) Decreasing the masonry content as well as increasing the cement content or the degree of compaction can enhance the unconfined compressive strength and the elastic modulus of cement treated demolition waste.

2) The cement content and the crushed masonry content play an equally important role in influencing the ratio of UCS to elastic modulus. Obtaining a high ratio value, one has to adjust the masonry content and the cement content.

3) The ratio of strength over modulus is considered as an indicator to design the cement treated base as a structural layer. Increasing the degree of compaction is an economical method to enhance the strength, but it is not an efficient method to enhance the admissible elastic strain and improve the flexural rigidity of cement treated layer.

It is recommended that optimization of the mechanical properties of cement treated demolition waste can be done by comprehensively considering all mixture variables. Meanwhile, its deformation behavior should be taken into account as well when optimizing its structural properties. 


\section{References}

[1] C. F. Hendriks and G. M. T. Janssen, "Reuse of construction and demolition waste in the Netherlands for road constructions," Heron, vol. 46, no. 2, pp. 109-117, 2001.

[2] S. Kolias and R. I. T. Williams, "Estimation of the modulus of elasticity of cement stabilized materials," Geotechnical Testing Journal, vol. 7, no.1, pp. 109-117, 1984.

[3] D. X. Xuan, L. J. M. Houben, A. A. A. Molenaar, and Z. H. Shui, "Cement treated recycled demolition waste as a road base material," Journal of Wuban University of Technology-Materials Science Edition, vol. 25, no. 4, pp. 696-699, 2010.

[4] R. L. Terrel, J. A. Epps, E. J. Barenberg, J. K. Mitchell, and M. R.Thompson, Soil Stabilization in Pavement Structures, a User's Manual-Volume 1: Pavement Design and Construction Considerations. Washington D.C.: Federal Highway Administration, Department of Transportation, 1979.

[5] G. K. Robinson, Practical Strategies for Experimenting. New York: Wiley, 2000, pp. 143-181.

[6] R. I. T. Williams, Cement-treated Pavements: Materials, Design, and Construction. London: Elsevier Applied Science Publishers, 1986, pp.206-243.

[7] R. L. Terrel, J. A. Epps, E. J. Barenberg, J. K. Mitchell, and M. R.Thompson, Soil Stabilization in Pavement Structures, a User's Manual-Volume 2: Mixture Design Considerations. Washington D.C.: Federal Highway Administration, Department of Transportation, 1979.

[8] T. C. Hansen, Recycling of Demolished Concrete and Masonry: Report of Technical Committee 37-DRC, Demolition and Reuse of Concrete, 1 st ed. New York: E \& FN Spon, 1992, pp. 168-170. 